\title{
https://doi.org/10.46813/2021-133-024 \\ STOCHASTIC MECHANISM OF BROADENING SPECTRAL DENSITY OF SYNCHROTRON RADIATION OF RELATIVISTIC ELECTRON
}

\author{
A.S. Mazmanishvili \\ National Science Center “Kharkov Institute of Physics and Technology”, Kharkiv, Ukraine \\ E-mail: mazmanishvili@gmail.com
}

The consideration is based on the study of the spectral profile of the synchrotron radiation (SR) line of a relativistic electron orbiting in a circular orbit in the uniform magnetic field. Fast stochastic fluctuations accompanying the motion of the electron during emission of SR quanta lead to the formation of spectral contour of each SR harmonic and it's broadening. It is shown that the joint broadening of the set of harmonics causes broadening of the SR spectrum as the whole. The results of numerical calculations on the formation of the final SR spectral density of a relativistic electron are presented. In order to obtain precision characteristics, the formation of SR density in the frequency range exceeding the critical frequency has been studied.

PACS: 29.20.-c, 41.60.Ap, 29.27.Fh

\section{INTRODUCTION}

It is known $[1,2]$ that in problems of quantum electrodynamics there are not so many examples that have a complete and exact solution. At the same time, the problem of finding the photon field emitted by a classical current, for example, a relativistic electron in a circular orbit in a uniform magnetic field, is an example of a completely solvable physical problem. A large number of works are devoted to synchrotron radiation (SR) of an ideal electron [3, 4]. There are known expressions describing the spectral properties of SR. The properties of SR of relativistic electrons, first of all, include its unconditional reproducibility and metrological calculability. Practical use of SR as a calibration radiation source makes it necessary to study both the reasons that can distort the ideal SR density and the degree of distortion. The paper considers fast fluctuations accompanying the motion of an electron during emission of SR quanta and leading to the formation of a contour of each SR harmonic and its broadening. The joint broadening of the set of harmonics causes broadening of the SR spectrum as a whole. An example of the numerical calculation for the formation of the final SR spectral density of a relativistic electron with energy of $100 \mathrm{MeV}$ is presented.

\section{THEORETICAL MODEL}

Below we will consider the field of photons emitted by an essentially classical distribution of electric current, which does not undergo a reverse reaction during radiation. Such a current can be represented as a vector function of coordinates and time $\vec{j}(\vec{r}, t)$.

Unlike the ideal case of circular motion of an electron in a uniform magnetic field with the Larmor frequency $\omega_{1}$, the real motion will never be monochromatic. In the ideal case the Hamiltonian $H_{1}$ of the first Larmor's harmonic of the field will have the form

$$
H_{1}=\hbar \omega_{1} a_{1}^{+}(t) a_{1}(t)
$$

and the time-dependent field operators $a_{1}^{+}(t)$ and $a_{1}(t)$ are specified in the absence of perturbations through the time-independent operators $a_{1}$ and $a_{1}^{+}$:

$$
a_{1}(t)=a_{1} \exp \left(-i \omega_{1} t\right), a_{1}^{+}(t)=a_{1}^{+} \exp \left(i \omega_{1} t\right) .
$$

Here we assume that the influence of interactions that violate the harmonic behavior of the oscillating field can be taken into account by adding to Hamiltonian $H_{1}$ (1) a term $H_{1 f}=\hbar f(t) a_{1}^{+} a_{1}$, which depends on a random function of time. Then, for the total Hamiltonian $\widetilde{H}_{1}$ of the first radiation mode, we obtain $\widetilde{H}_{1}=H_{1}+H_{1 f}$. Since the stochastic Hamiltonian $H_{1 f}$ commutes with $H_{1}$, we can consider the Schrödinger equation [1]

$$
i \frac{\partial}{\partial t} U_{f}\left(t, t^{\prime}\right)=f(t) a_{1}^{+} a_{1} U_{f}\left(t, t^{\prime}\right)
$$

for the unitary operator $U_{f}\left(t, t^{\prime}\right)$ that obeys the initial condition $U_{f}\left(t^{\prime}, t^{\prime}\right)=1$. His solution is

$$
U_{f}\left(t, t^{\prime}\right)=\exp \left\{-i a_{1}^{+} a_{1} \int_{t^{\prime}}^{t} f(\tau) d \tau\right\} .
$$

If, due to the classical nature of the current $\vec{j}(\vec{r}, t)$, the field at the initial moment of time $t=0$ was in coherent state $\alpha_{0}$, then at the moment of time $t$ this state will be

$$
\left|\alpha_{1}\right\rangle=\left|\alpha_{0} \exp \left\{-i \omega_{1} t-i \int_{0}^{t} f(\tau) d \tau\right\}\right\rangle .
$$

Here we assume that the random function $f(\tau)$ is a stationary Gaussian process with $\delta$-shaped time correlate operator. Let us find the spectral density $w_{1}(\omega)$ of the average number of photons in the Larmor's mode

$$
\begin{aligned}
& w_{1}(\omega)=\left|\alpha_{1}\right|^{2} \int d \tau \exp \left\{-i\left(\omega-\omega_{1}\right) \tau-J_{1}\right\}, \\
& J_{1}=\frac{1}{2} \int_{0}^{\tau} d t_{1} \int_{0}^{\tau} d t_{2}\left\langle f\left(t_{1}\right) f\left(t_{2}\right)\right\rangle .
\end{aligned}
$$

From (5) it follows that the main contribution to the broadening of the line contour will come from that $f^{*}(t)$ part of the process $f(t)$ for which its correlate operator contains the $\delta$-function 


$$
\left\langle f^{*}\left(t_{1}\right) f^{*}\left(t_{2}\right)\right\rangle=2 \mu \omega_{1} \delta\left(t_{1}-t_{2}\right),
$$

where $\mu$ is the diffusion coefficient. Property (6) is possessed, in particular, by such stochastic processes as the scattering of electrons with each other, as well as fluctuations caused by the emission of SR quanta [3]. For the latter, you can get

$$
\left\langle f^{*}\left(t_{1}\right) f^{*}\left(t_{2}\right)\right\rangle=\frac{\omega_{1} \rho^{2}}{E} \frac{R}{\langle R\rangle} \frac{\left\langle\varepsilon_{q}^{2}\right\rangle}{4 \alpha_{s}} \dot{N} \delta\left(t_{1}-t_{2}\right),
$$

where $\rho$ is the orbital densification coefficient, $E$ is the electron energy, $R$ is the radius of curvature of the orbit, $\langle R\rangle$ is the average radius, $\left\langle\varepsilon_{q}^{2}\right\rangle$ is the average square of the energy of the emitted quanta, $\alpha_{s}$ is the damping coefficient of synchrotron oscillations, $\dot{N}$ is the frequency of emission of quanta. From here we can write

$$
\mu=\frac{165}{24 \sqrt{3} \pi} \frac{R^{2} \Lambda}{\langle R\rangle^{3}} \frac{\gamma^{2}}{(1-n)(3-4 n)},
$$

where $\gamma$ is the relativistic factor, $\Lambda$ is the Compton wavelength of the electron, $n$ is the decay rate of the guiding magnetic field. Now, for the spectral density of the average number of photons $w_{1}(\omega)$ in the Larmor's mode, after integration into (5), we obtain the Lorentz line contour

$$
w_{1}(\omega)=\frac{w_{1}}{\pi} \frac{\mu \omega_{1}}{\left(\omega-\omega_{1}\right)^{2}+\left(\mu \omega_{1}\right)^{2}},
$$

in which $w_{1}$ is the total number of photons in the mode. The contour (9) of the first mode has a width $\Delta \omega_{1}=\mu \omega_{1}$ proportional to diffusion coefficient $\mu$.

In the absence of stochastic perturbations of the ideal equilibrium orbit of an electron, the spectral line profile of the first Larmor's mode has zero width. From (9) it follows that phase fluctuations leave the total radiation power $w_{1}$ in the Larmor mode unchanged, having a noticeable effect on its spectral composition. Similarly to the spectral analysis of the first mode, one can consider the contour of the $m$-th harmonic of the radiation. We write the Hamiltonian $\widetilde{H}_{m}$ of the $m$-th harmonic of the field in the form

$$
\widetilde{H}_{m}=\hbar \omega_{m} a_{m}^{+}(t) a_{m}(t)(1+f(t)),
$$

where $\omega_{m}=m \omega_{1}$ is the central frequency of the $m$-th mode. Then, for coherent state $\left|\alpha_{m}\right\rangle$, we write

$$
\left|\alpha_{m}\right\rangle=\left|\alpha_{m 0} \exp \left\{-i m \omega_{1} t-i m \int_{0}^{t} f(\tau) d \tau\right\}\right\rangle,
$$

which leads to the integral for the spectral density

$$
\begin{aligned}
& w_{m}(\omega)=\left|\alpha_{m}\right|^{2} \int d \exp \left\{-i\left(\omega-m \omega_{1}\right) \tau-J_{m}\right\}, \\
& J_{m}=\frac{m^{2}}{2} \int_{0}^{\tau} d t_{1} \int_{0}^{\tau} d t_{2}\left\langle f\left(t_{1}\right) f\left(t_{2}\right)\right\rangle .
\end{aligned}
$$

Note that in (12) the quadratic in the mode number $m$ is due to the normal property of the considered noise $f(t)$. After transformations, we get

$$
w_{m}(\omega)=\frac{w_{m}}{\pi} \frac{\mu \omega_{1} m^{2}}{\left(\omega-m \omega_{1}\right)^{2}+\left(\mu \omega_{1} m^{2}\right)^{2}},
$$

where $w_{m}$ is the number of quanta stored in the $m$-th mode. In (13), the Lorentz contour of the $m$-th mode is concentrated around the frequency $\omega_{m}=m \omega_{1}$ and has a linewidth $\Delta \omega_{m}=\mu \omega_{1} m^{2}$. With the average number of quanta $w_{m}$ in the mode, they are statistically independent and distributed according to Poisson's law.

In the ideal case $\mu \rightarrow 0$, the spectrum of the SR photon flux is described by a set of a large number of harmonics with zero width each. Their multitude extends to the region of harmonics with a critical number $m_{c}=3 \gamma^{3} / 2$ and further, which corresponds to the critical frequency $\omega_{c}=m_{c} \omega_{1}$. Since $m_{c}>>1$, to describe the ideal SR spectrum, it is customary to use a function $W(\omega)$ that describes the envelope of the specified set of harmonics [3].

In the presence of perturbations, the resulting spectrum $W_{\mu}(\omega)$ of the SR photon flux should be the result of the convolution of an ideal spectrum $W(\omega)$ with an inhomogeneous Lorentzian kernel

$$
\begin{aligned}
& W_{\mu}(\omega)=B \int_{0}^{\infty} \frac{d z}{\pi} \int_{0}^{\infty} d x \exp (-z \cosh x) \times \\
& \times \frac{\cosh (5 x / 3)}{\cosh x} \frac{\mu \omega_{1} m_{c}^{2} z^{2}}{\left(\omega-\omega_{c} z\right)^{2}+\left(\mu \omega_{1} m_{c}^{2} z^{2}\right)^{2}}
\end{aligned}
$$

where $B$ is a factor depending on the parameters of the system. Result (14) can be written in a form, in which the integral contribution of the broadening of all modes spectral contours to the resulting SR spectrum is more clearly seen,

$$
\begin{aligned}
& W_{\mu}(\omega)=B \int_{0}^{\infty} \frac{d u}{\pi} \int_{0}^{\infty} d x \exp (-u \cosh x) \times \\
& \times \frac{\cosh (5 x / 3)}{\cosh x} \frac{\mu m_{c} u^{2}}{\left(u-\omega / \omega_{c}\right)^{2}+\left(\mu m_{c} u^{2}\right)^{2}} .
\end{aligned}
$$

In the absence of perturbation, by passing to the limit $\mu \rightarrow 0$, we can obtain from (15) an expression for the ideal SR spectral density $W(\omega)$, which corresponds to the set of all harmonics with a line contour of the type $\delta\left(\omega-m \omega_{1}\right)$ each,

$$
W(\omega)=B \int_{0}^{\infty} \exp \left(-\frac{\omega}{\omega_{c}} \cosh x\right) \frac{\cosh (5 x / 3)}{\cosh x} d x .
$$

Let us present the result of a numerical calculation of the spectral density of the number of emitted SR quanta in the range of frequencies adjacent to $\omega_{c}$, for the N-100 KIPT electron storage ring [5]. Installation 
parameters: $E=100 \mathrm{MeV}, \omega_{1}=94.8 \mathrm{MHz}, \quad \gamma=196$, $R=50 \mathrm{~cm},\langle R\rangle=91 \mathrm{~cm}, \omega_{c}=1.07 \cdot 10^{15} \mathrm{~Hz}, n=0.27$.

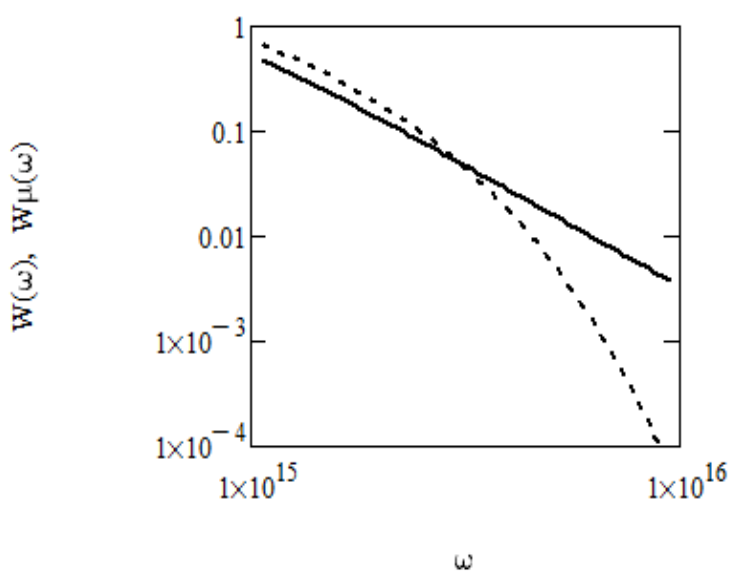

Fig. 1. The ideal spectral density $W(\omega)$ at $\mu \rightarrow 0$

(dotted line) and the resulting density $W_{\mu}(\omega)$

(solid line), $B$ is taken equal to 1

The densities $W(\omega)$ and $W_{\mu}(\omega)$ are shown in

Fig. 1. At the frequency $\omega=\omega_{c}$, the resulting spectrum $W_{\mu}(\omega)$ is $74 \%$ of the spectrum $W(\omega)$. At higher frequencies $\left(\omega \geq 3 \omega_{c}\right) \quad W_{\mu}(\omega)$ exceeds $W(\omega)$ due to Lorentz broadening (see Fig. 2).

In this case, the integral radiated energy to the SR remains unchanged. The asymptotic behavior $W_{\mu}(\omega)$ of the frequency can be approximated by the dependence $\omega^{-2}$, which follows from (15).

Note that additional averaging of the spectrum $W(\omega)$ over the energy distribution of electrons in the beam will not change the exponential decay of the photon spectrum in the threshold region $\omega \geq \omega_{c}$.

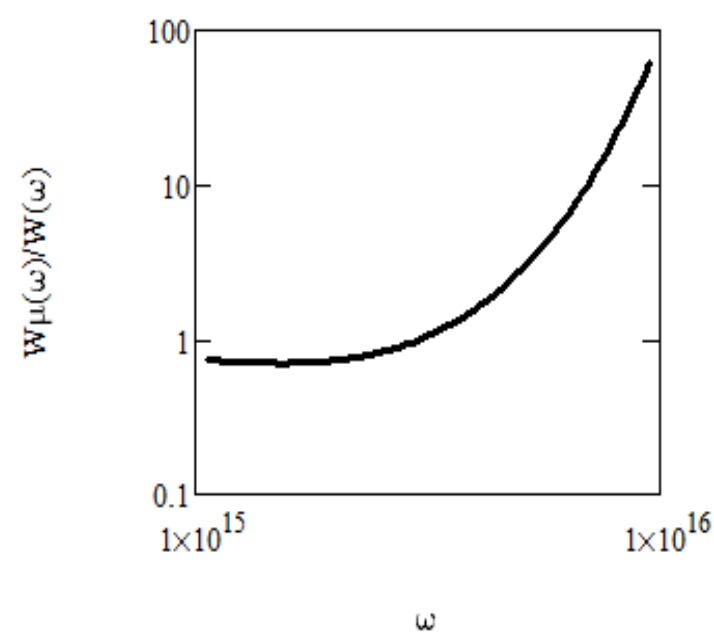

Fig. 2. Ratio of ideal spectral density $W(\omega)$

$$
\text { to density } W_{\mu}(\omega)
$$

\section{DISCUSSION}

The relativistic electron emitting in a magnetic field can be associated with the model of a multimode regular resonator, in which the number of modes is large reaching $\gamma^{3}$ or more. The energy $\varepsilon_{i}$ of the emitted quantum and the moment $t_{i}$ of its emission are not related in any way. Therefore, these quantities can be considered as independent random variables. They satisfy the requirements of the central limit theorem $[3,6]$. In this case, the mechanism for the formation of the spectral contour of the radiation in the first mode was developed $[1,2]$ and can be extended for a mode with an arbitrary number, as well as their combination.

\section{CONCLUSIONS}

The orbital revolution of electrons is accompanied by fast fluctuations arising from the emission of SR quanta. This leads to the broadening of the contour in the Larmor mode and in each of the SR harmonics. The result of joint broadening of the set of harmonics causes distortion of the spectrum, that is, broadening of the synchrotron radiation spectrum as a whole in the frequency range adjacent to and exceeding the critical radiation frequency $\omega_{c}$. The integral radiated energy to the SR remains unchanged. Spectral density in the frequency range $\omega \leq \omega_{c}$ remains stable and stationary, in the region $\omega \approx \omega_{c}$ it decreases. In the range of frequencies $\omega_{c}$ exceeding the critical one it increases.

\section{REFERENCES}

1. R. Glauber. Optical coherence and photon statistics // Quantum optics and quantum radiophysics. M.: "Mir", 1966, p. 91-280.

2. J. Wanter. The theory of line width // Quantum optics and quantum radiophysics. M.: “Mir", 1966, p. $377-451$.

3. G. Brook. Cyclic accelerators of charged particles. M.: "Atomizdat", 1970, p. 311.

4. I.M. Ternov, V.V. Mikhailin, V.R. Khalilov. Synchrotron radiation and its applications. M.: "MGU", 1980, p. 278.

5. Yu.N. Grigoriev, I.A. Grishaev, A.N. Dovbnya, et al. Electron storage ring with energy $100 \mathrm{MeV} / /$ Atomic Energy. 1967, v. 23, p. 531-536.

6. A.A. Kolomensky, A.N. Lebedev. The theory of cyclic accelerators. M.: "Fizmatgiz", 1962, p. 352.

Article received 20.04.2021 


\section{СТОХАСТИЧЕСКИЙ МЕХАНИЗМ УШИРЕНИЯ СПЕКТРАЛЬНОЙ ПЛОТНОСТИ СИНХРОТРОННОГО ИЗЛУЧЕНИЯ РЕЛЯТИВИСТСКОГО ЭЛЕКТРОНА}

\section{А.С. Мазманишвили}

Рассмотрение опирается на изучение формирования спектрального контура линии синхротронного излучения (СИ) релятивистского электрона, вращающегося по круговой орбите в однородном магнитном поле. Быстрые стохастические флуктуации, сопровождающие движение электрона при эмиссии квантов СИ, приводят к формированию спектрального контура каждой из гармоник СИ и его уширению. Показано, что совместное уширение совокупности гармоник обуславливает уширение спектра СИ в целом. Представлены результаты численных расчетов по формированию итоговой спектральной плотности СИ релятивистского электрона. С целью получения прецизионных характеристик изучено формирование плотности СИ в области частот, превышающих критическую частоту.

\section{СТОХАСТИЧНИЙ МЕХАНІЗМ РОЗШИРЕННЯ СПЕКТРАЛЬНОЇ ЩІЛЬНОСТІ СИНХРОТРОННОГО ВИПРОМІНЮВАННЯ РЕЛЯТИВІСТСЬКОГО ЕЛЕКТРОНА}

\section{О.С. Мазманішвілі}

Розгляд спирається на вивчення спектрального контуру лінії синхротронного випромінювання (СВ) релятивістського електрона, що обертається по круговій орбіті в однорідному магнітному полі. Швидкі стохастичні флуктуації, які супроводжують рух електрона при емісії квантів $\mathrm{CB}$, призводять до формування спектрального контуру кожної з гармонік СВ і його розширенню. Показано, що спільне розширення сукупності гармонік обумовлює розширення спектра СВ у цілому. Представлені результати чисельних розрахунків по формуванню підсумкової спектральної щільності СВ релятивістського електрона. 3 метою отримання прецизійних характеристик вивчено формування щільності СВ в області частот, що перевищують критичну частоту. 